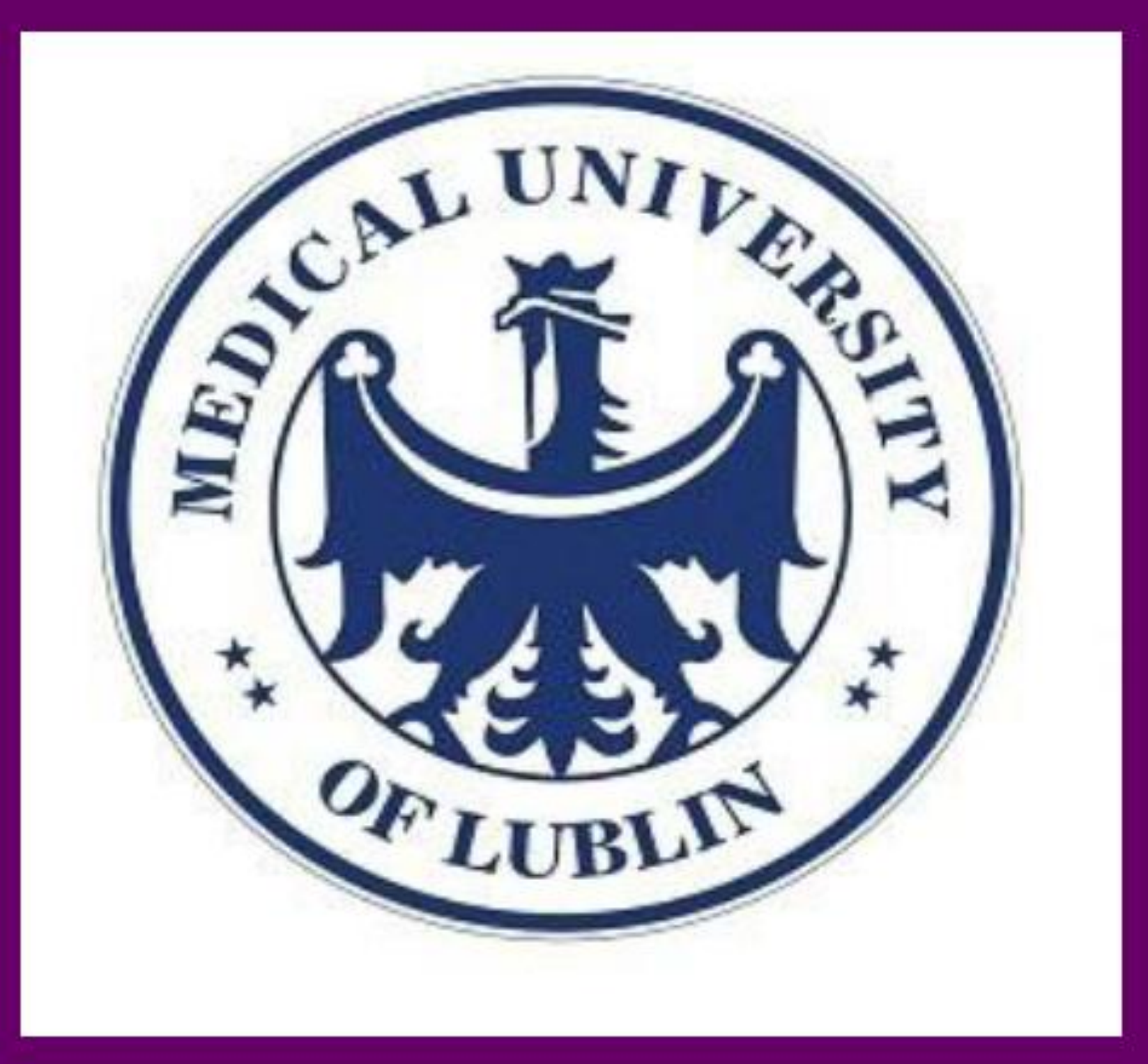

\title{
ENDOCRINE DISORDERS IN WOMEN WITH TURNER SYNDROME
}

\author{
Agnieszka Zwolak ${ }^{1,2}$, Anna M.Dąbrowska' ${ }^{1}$, Jerzy S.Tarach ${ }^{1}$ \\ ${ }^{1}$ Chair and Department of Endocrinology, Medical University of Lublin, Poland \\ ${ }^{2}$ Chair of Internal Medicine and Department of Internal Medicine in Nursing, Medical University of Lublin, Poland
}

INTRODUCTION: Turner syndrome (TS) is the most common chromosomal abnormality in women. It occurs in $1 / 2,500$ to $1 / 3,000$ live-born females and results from a total or partial absence of the $\mathbf{X}$ chromosome. The clinical manifestations are diverse and TS is accompanied by multiple medical problems.
METHODS: We analyzed retrospectively 6 cases of women with TS aged 20-66 years, treated at Endocrinology Department between 2003 and 2014, to describe endocrine disorders in such patients. In the studied subjects, the diagnosis of TS was made in childhood (1 patient), in adolescence (3 cases) or in adulthood ( 2 women), based on clinical symptoms as well as genetic tests.

\section{RESULTS:}

3 women with short stature received recombinant human growth hormone. The average height was $152.5 \pm 6.53 \mathrm{~cm}$. None of patients were obese (BMI: $24.12 \pm 2.88 \mathrm{~kg} / \mathrm{m}^{2}$ ). Sex hormone replacement therapy was used by 4 women, 2 the oldest non-treated patients suffered from osteoporosis. Subjects with hypothyroidism due to Hashimoto's thyroiditis used levothyroxine. Patient with type 1 diabetes had many diabetic complications such as: coronary heart disease, cerebrovascular disease, peripheral vascular disease, sensory neuropathy, diabetic amyotrophy, glaucoma, cataract.

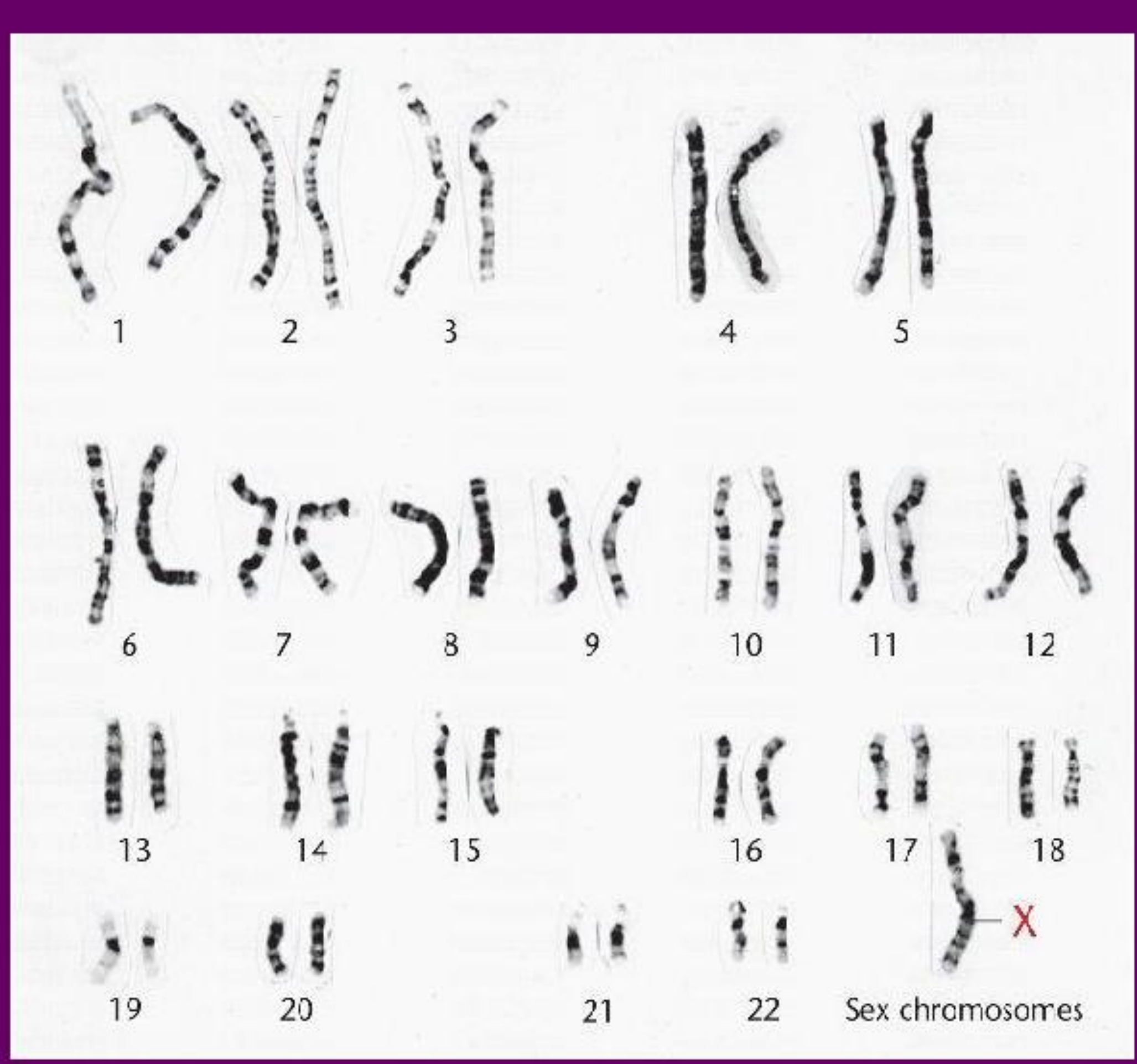

Fig. 1. Karyotype of Turner syndrome (Ref. www.geoset.info)

\begin{tabular}{|l|c|}
\multicolumn{1}{|c|}{$\begin{array}{c}\text { ENDOCRINE DISORDERS } \\
\text { in TS }\end{array}$} & $\begin{array}{c}\text { NUMBER of PATIENTS } \\
(\mathbf{n = 6})\end{array}$ \\
\hline - short stature & 6 \\
\hline - primary amenorrhea & 5 \\
\hline - premature ovarian insufficiency & 1 \\
\hline - clitoromegaly & 1 \\
\hline - leukoplakia vulvae & 1 \\
\hline - hypothyroidism due to Hashimoto's \\
thyroiditis
\end{tabular}

Moreover other non-endocrine diseases were observed, including: coeliac disease ( 2 cases), hypertension ( 3 patients), mitral incompetence and tricuspid regurgitation (1 woman), impaired hearing ( 2 subjects), ectopic or horseshoe kidney ( 2 cases).

The intellectual performance was within the normal range in 4 women, 2 patients were mentally retarded.

CONCLUSIONS: Most of subjects with TS have hormonal disorders. Therefore, endocrine care is needed to optimize patients' treatment. 